\title{
ORIGINAL
}

ARTICLES

\section{Conditions Influencing Collaboration Among the Primary Care Disciplines as They Prepare the Future Primary Care Physician Workforce}

Patricia A. Carney, PhD, MS; Erin K. Thayer, BA; Larry A. Green, MD; Eric J. Warm, MD;

Eric S. Holmboe, MD, MACP; Carol Carraccio, MD, MS; M. Patrice Eiff, MD

BACKGROUND AND OBJECTIVES: Much can be gained by the three primary care disciplines collaborating on efforts to transform residency training toward interprofessional collaborative practice. We describe findings from a study designed to align primary care disciplines toward implementing interprofessional education.

METHODS: In this mixed methods study, we included faculty, residents and other interprofessional learners in family medicine, internal medicine, and pediatrics from nine institutions across the United States. We administered a webbased survey in April/May of $\mathbf{2 0 1 8}$ and used qualitative analyses of field notes to study resident exposure to team-based care during training, estimates of career choice in programs that are innovating, and supportive and challenging conditions that influence collaboration among the three disciplines. Complete data capture was attained for $96.3 \%$ of participants.

RESULTS: Among family medicine resident graduates, an estimated $\mathbf{8 7 . 1 \%}$ chose to go into primary care compared to $12.4 \%$ of internal medicine, and $36.5 \%$ of pediatric resident graduates. Qualitative themes found to positively influence cross-disciplinary collaboration included relationship development, communication of shared goals, alignment with health system/other institutional initiatives, and professional identity as primary care physicians. Challenges included expressed concerns by participants that by working together, the disciplines would experience a loss of identity and would be indistinguishable from one another. Another qualitative finding was that overwhelming stressors plague primary care training programs in the current health care climate-a great concern. These include competing demands, disruptive transitions, and lack of resources.

CONCLUSIONS: Uniting the primary care disciplines toward educational and clinical transformation toward interprofessional collaborative practice is challenging to accomplish.

(Fam Med. 2020;52(X):XX-X.)

doi: 10.22454/FamMed.2020.741660

Published Online First March 16, 2020

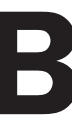
y 2025 , an additional $44,000-$ 51,000 primary care physicians will be needed to provide patient care due to increases in health care utilization caused by population growth, aging, and insurance expansion associated with the Affordable Care Act. ${ }^{1-4}$ Geographic maldistribution of primary care physicians contributes additional complexities. ${ }^{5,6}$ Within these contexts, an additional concern is whether primary care-a discipline worthy of physicians devoting their careers to-will survive given declining trends in choosing careers in general internal medicine and general pediatrics versus subspecialty or hospitalist care, and declines in US medical students choosing family medicine residencies. ${ }^{7,8}$ Changes are needed to address these challenges.

Family medicine (FM), internal medicine (IM), and pediatrics (Peds) undertook separate discipline-specific residency redesign initiatives between 2007 and 2009 to better prepare residents for future practice. $^{9-11}$ Then, while forecasting the

From the Oregon Health \& Science University, Portland, OR (Drs Carney and Eiff, and Ms Thayer); University of Colorado, Denver, CO (Dr Green); University of Cincinnati, Cincinnati, $\mathrm{OH}$ (Dr Warm); Accreditation Council for Graduate Medical Education, Chicago, IL (Dr Holmboe); and American Board of Pediatrics, Chapel Hill, NC (Dr Carraccio). 
need to dramatically improve our primary care delivery system, the three certifying boards united in 2009 to pilot test a collaborative model on residency training and clinical redesign. This joint project, the Primary Care Faculty Development Initiative (PCFDI), ${ }^{12,13}$ prepared faculty to accelerate change in primary care residency training by working to unite them in a common mission to create effective ambulatory clinical learning environments. Thirty-six faculty from four institutions and 12 affiliated primary care residency training programs (FM, IM, and Peds) participated. Results demonstrated that faculty in the primary care disciplines, who prior to PCFDI had little contact with each other, could come together successfully around patient-centered medical home (PCMH) transformation and transdisciplinary training. ${ }^{13}$ Twelve months after PCFDI training, faculty members' confidence in leadership improved significantly for $15 / 19(79 \%)$ variables assessed, and their self-assessed skills improved significantly for 21/22 (95\%) competencies. ${ }^{13}$

Based on the success of PCFDI, a larger, more comprehensive initiative was undertaken in 2015 with support from the American Board of Family Medicine Foundation, the American Board of Internal Medicine Foundation, the American Board of Pediatrics Foundation, the Josiah Macy Jr Foundation, and the Accreditation Council for Graduate Medical Education. ${ }^{14}$ This new initiative, Professionals Accelerating Clinical and Educational Redesign (PACER), involved nine institutions, 27 primary care residency training programs, and other health professions programs who collaborated educationally and clinically to provide team-based care in ambulatory settings toward achieving the triple aim. ${ }^{15}$ The study's main effects are reported elsewhere. ${ }^{16}$ The purpose of this article is to: (1) describe efforts to align primary care disciplines in residency continuity clinics, (2) report resident exposure to team-based care during training, (3) calculate estimates of career choice in programs that are innovating, and (4) identify supportive and challenging conditions that influence collaboration among the three disciplines.

\section{Methods}

\section{The PACER Initiative}

The nine PACER sites were selected using a competitive process that involved submitting a proposal that united FM, IM, and Peds in educational innovation. Proposals included in-depth descriptions of their respective primary care physician residency continuity practices $(n=27)$. Each site recruited an interprofessional team in addition to faculty from FM, IM, and Peds, including nursing, physician assistant, pharmacy, and behavioral health. Proposals addressed planned innovative changes in training that would better prepare residents to work within and across primary care and other health professions disciplines. A review group that included members of a steering committee with representatives from the three primary care clinics reviewed scored and ranked proposals, with the top nine being selected.

PACER intervention elements were designed to facilitate implementation of their own planned strategies as well as comprehensive assessments of them. Intervention activities included two 1.5-day training sessions, routine coaching sessions from an expert in interprofessional education redesign, site visits, and webinars.

\section{Study Design and Data Collection}

A quasi-experimental mixed-methods design guided this study. The quantitative aspects included surveying FM, IM, and Peds faculty on residency size overall, the number of residents training in the PACER continuity clinic, other health professions trainees in the same clinic, and the proportion of residents estimated by residency faculty to enter primary care practice, pursue fellowship training, or become hospitalists.
The web-based survey was administered at the end of the PACER study (April/May 2018). The response rate to the survey and follow-up calls were high, at $96.3 \%$.

Because recent data suggests interprofessional practice (IPP) is associated with improved patient outcomes, ${ }^{17}$ we also surveyed continuity clinics on the extent to which interprofessional team-based learning was occurring in the PACER clinics. We defined interprofessional team-based learning as learning arising from interactions between members or students of two or more professions which may be a product of interprofessional education or happen spontaneously in the workplace or in education settings and therefore be serendipitous in nature. ${ }^{18}$

The qualitative approach involved analyses of reports associated with the study, including needs-assessments conducted at the start of the study, site visit observations and inperson interviews done during the study, and telephone interviews with study team members done at the end of the study. The specific research question that the qualitative analysis sought to address was: "What factors influence the ability of the primary care disciplines to collaborate on transforming their residency training to improve the primary care workforce?" Oregon Health \& Science University's Institutional Review Board approved all study activities (IRB \#11932).

\section{Data Analyses}

Quantitative data were analyzed using descriptive statistics. Qualitative analyses involved creating two composite documents of all relevant study materials. One included initial needs assessments and the site visit reports, and the second document included the final debriefing phone call that occurred at the end of the study. Multiple independent recorders contributed to the composite documents. Two study team members (authors P.A.C. and E.K.T.) first individually open coded relevant passages and phrases in composite reports and 
then compared codes during five consensus meetings held between May 2018 and July 2018. The consensus open codes were applied to the composite reports. This process was repeated until coding was complete which included combining, eliminating and refining codes using constant comparative analyses. ${ }^{19}$ Code saturation was achieved when no new codes were applied to the data, which occurred at Meeting 5 and saturated open codes were applied to the remaining composite reports. The analysis team then conducted axial coding $^{20}$ and determined definitions for the selective codes in the form of themes and subthemes for each code category. We then selected exemplar statements from composite reports to illustrate these themes.
Results

Many regions of the country were represented and sizes of programs varied (Table 1) with a range in FM residents trained in PACER clinics of 19-39, for IM residents the range was 22-100, and for Peds residents the range was 9-86. Physician trainees most often interacted with medical, nurse practitioner, physician assistant, and pharmacy students.

Table 1: Characteristics of Participating Institutions and Primary Care Residency Programs

\begin{tabular}{|c|c|c|c|c|}
\hline Institution & $\begin{array}{l}\text { US } \\
\text { Census } \\
\text { Region }\end{array}$ & $\begin{array}{l}\text { Discipline } \\
\text { \# Residents in } \\
\text { PACER/Total } \\
\text { \# Residents } \\
\text { in Program }\end{array}$ & $\begin{array}{l}\text { \# Residents in } \\
\text { PACER Continuity } \\
\text { Clinics } \\
\text { (By Program Year) }\end{array}$ & Other Trainees in PACER Continuity Clinics \\
\hline \multirow{3}{*}{1} & \multirow{3}{*}{ West } & $\underset{\mathrm{n}=19 / 31}{\mathrm{FM}}$ & $\begin{array}{l}\text { PGY1: } 8 \\
\text { PGY2: } 6 \\
\text { PGY3: } 5\end{array}$ & $\begin{array}{l}\text { Medical students, nurse practitioner students, physician } \\
\text { assistant students, PharmD students, clinical psychology } \\
\text { students, MSW/LCSW students, medical assistant students, } \\
\text { psychiatry residents, psychology residents, MPH students, } \\
\text { PharmD residents }\end{array}$ \\
\hline & & $\underset{\mathrm{n}=30 / 167}{\mathrm{IM}}$ & $\begin{array}{l}\text { PGY1: } 10 \\
\text { PGY2: } 10 \\
\text { PGY3: } 10\end{array}$ & $\begin{array}{l}\text { Medical students, nurse practitioner students, PharmD } \\
\text { students, medical assistant students }\end{array}$ \\
\hline & & $\begin{array}{c}\text { Peds } \\
n=9 / 90\end{array}$ & $\begin{array}{l}\text { PGY1: } 4 \\
\text { PGY2: } 3 \\
\text { PGY3: } 2\end{array}$ & $\begin{array}{l}\text { Medical students, nursing students, physician assistant } \\
\text { students, clinical psychology students, MSW/LCSW students, } \\
\text { medical assistant students }\end{array}$ \\
\hline \multirow{3}{*}{2} & \multirow{3}{*}{ South } & $\begin{array}{c}\text { FM } \\
\mathrm{n}=39 / 39\end{array}$ & $\begin{array}{l}\text { PGY1: } 14 \\
\text { PGY2: } 13 \\
\text { PGY3: } 12\end{array}$ & Medical students, physician assistant students \\
\hline & & $\begin{array}{c}\mathrm{IM} \\
\mathrm{n}=22 / 36\end{array}$ & $\begin{array}{l}\text { PGY1: } 7 \\
\text { PGY2: } 7 \\
\text { PGY3: } 8\end{array}$ & Nurse practitioner students \\
\hline & & $\begin{array}{c}\text { Peds } \\
\mathrm{n}=66 / 66\end{array}$ & $\begin{array}{l}\text { PGY1: } 22 \\
\text { PGY2: } 22 \\
\text { PGY3: } 22\end{array}$ & $\begin{array}{l}\text { Medical students, nursing students, nurse practitioner } \\
\text { students, physician assistant students, dental students, } \\
\text { clinical psychology students, MSW/LCSW students, medical } \\
\text { assistant students }\end{array}$ \\
\hline \multirow{3}{*}{3} & \multirow{3}{*}{ Midwest } & $\begin{array}{c}\text { FM } \\
\mathrm{n}=24 / 24\end{array}$ & $\begin{array}{l}\text { PGY1: } 8 \\
\text { PGY2: } 8 \\
\text { PGY3: } 8\end{array}$ & Medical students, nursing students, PharmD students \\
\hline & & $\underset{\mathrm{n}=100 / 148}{\mathrm{IM}}$ & $\begin{array}{l}\text { PGY1: } 35 \\
\text { PGY2: } 33 \\
\text { PGY3: } 32\end{array}$ & Medical students, PharmD students and residents \\
\hline & & $\begin{array}{l}\begin{array}{c}\text { Peds } \\
n=40 / 40\end{array}\end{array}$ & $\begin{array}{l}\text { PGY1: } 14 \\
\text { PGY2: } 14 \\
\text { PGY3: } 12\end{array}$ & $\begin{array}{l}\text { Medical students, nursing students, nurse practitioner } \\
\text { students, PharmD students }\end{array}$ \\
\hline \multirow{3}{*}{4} & \multirow{3}{*}{$\begin{array}{l}\text { Mid- } \\
\text { Atlantic }\end{array}$} & $\begin{array}{c}\mathrm{FM} \\
\mathrm{n}=21 / 21\end{array}$ & $\begin{array}{l}\text { PGY1: } 7 \\
\text { PGY2: } 7 \\
\text { PGY3: } 7\end{array}$ & Medical students, nurse practitioner students \\
\hline & & $\underset{\mathrm{n}=60 / 108}{\mathrm{IM}}$ & $\begin{array}{l}\text { PGY1: } 20 \\
\text { PGY2: } 20 \\
\text { PGY3: } 20\end{array}$ & $\begin{array}{l}\text { Medical students, physician assistant students, PharmD } \\
\text { students, clinical psychology students }\end{array}$ \\
\hline & & $\begin{array}{c}\text { Peds } \\
n=86 / 99\end{array}$ & $\begin{array}{l}\text { PGY1: } 30 \\
\text { PGY2: } 28 \\
\text { PGY3: } 28\end{array}$ & $\begin{array}{l}\text { Medical students, nurse practitioner students, physician } \\
\text { assistant students, dental students }\end{array}$ \\
\hline
\end{tabular}


Table 1: Continued

\begin{tabular}{|c|c|c|c|c|}
\hline Institution & $\begin{array}{l}\text { US } \\
\text { Census } \\
\text { Region }\end{array}$ & $\begin{array}{c}\text { Discipline } \\
\text { \# Residents in } \\
\text { PACER/Total } \\
\text { \# Residents } \\
\text { in Program }\end{array}$ & $\begin{array}{c}\text { \# Residents in } \\
\text { PACER Continuity } \\
\text { Clinics } \\
\text { (By Program Year) }\end{array}$ & Other Trainees in PACER Continuity Clinics \\
\hline \multirow{3}{*}{5} & \multirow{3}{*}{ West } & $\begin{array}{l}\mathrm{FM} \\
\mathrm{n}=44 / 44\end{array}$ & $\begin{array}{l}\text { PGY1: } 15 \\
\text { PGY2: } 13 \\
\text { PGY3: } 16\end{array}$ & Medical students, PharmD students \\
\hline & & $\begin{array}{l}\mathrm{IM} \\
\mathrm{n}=62 / 69\end{array}$ & $\begin{array}{l}\text { PGY1: } 20 \\
\text { PGY2: } 21 \\
\text { PGY3: } 21\end{array}$ & PharmD students, medical assistant students \\
\hline & & $\begin{array}{l}\text { Peds } \\
\mathrm{n}=12 / 39\end{array}$ & $\begin{array}{l}\text { PGY1: } 3 \\
\text { PGY2: } 4 \\
\text { PGY3: } 5\end{array}$ & Medical assistant students \\
\hline \multirow{3}{*}{6} & \multirow{3}{*}{ West } & $\begin{array}{l}\mathrm{FM} \\
\mathrm{n}=18 / 36\end{array}$ & $\begin{array}{l}\text { PGY1: } 6 \\
\text { PGY2: } 6 \\
\text { PGY3: } 6 \\
\end{array}$ & Medical students, nurse practitioner students \\
\hline & & $\begin{array}{l}\mathrm{IM} \\
\mathrm{n}=27 / 54\end{array}$ & $\begin{array}{l}\text { PGY1: } 9 \\
\text { PGY2: } 10 \\
\text { PGY3: } 8\end{array}$ & $\begin{array}{l}\text { Medical students, nursing students, PharmD students, } \\
\text { MSW/LCSW students }\end{array}$ \\
\hline & & $\begin{array}{l}\text { Peds } \\
\mathrm{n}=36 / 36\end{array}$ & $\begin{array}{l}\text { PGY1: } 12 \\
\text { PGY2: } 12 \\
\text { PGY3: } 12 \\
\end{array}$ & $\begin{array}{l}\text { Medical students, nursing students, nurse practitioner } \\
\text { students, MSW/LCSW students, medical assistant students }\end{array}$ \\
\hline \multirow{3}{*}{7} & \multirow{3}{*}{ South } & $\begin{array}{l}\mathrm{FM} \\
\mathrm{n}=30 / 30\end{array}$ & $\begin{array}{l}\text { PGY1: } 10 \\
\text { PGY2: } 10 \\
\text { PGY3: } 10\end{array}$ & $\begin{array}{l}\text { Medical students, physician assistant students, PharmD } \\
\text { students, }\end{array}$ \\
\hline & & $\begin{array}{l}\mathrm{IM} \\
\mathrm{n}=33 / 33\end{array}$ & $\begin{array}{l}\text { PGY1: } 11 \\
\text { PGY2: } 11 \\
\text { PGY3: } 11 \\
\end{array}$ & $\begin{array}{l}\text { Medical students, nursing students, PharmD students, } \\
\text { MSW/LCSW students }\end{array}$ \\
\hline & & $\begin{array}{l}\text { Peds } \\
\mathrm{n}=0 / 36^{*}\end{array}$ & $\begin{array}{l}\text { PGY1: 0* } \\
\text { PGY2: 0* } \\
\text { PGY3: 0* }\end{array}$ & $\begin{array}{l}\text { Medical students, nursing students, LPN students, MHA } \\
\text { students, counseling interns, pharmacy residents }\end{array}$ \\
\hline \multirow{3}{*}{8} & \multirow{3}{*}{ Midwest } & $\begin{array}{l}\mathrm{FM} \\
\mathrm{n}=26 / 26\end{array}$ & $\begin{array}{l}\text { PGY1: } 9 \\
\text { PGY2: } 8 \\
\text { PGY3: } 9 \\
\end{array}$ & Medical students, PharmD students \\
\hline & & $\begin{array}{l}\mathrm{IM} \\
\mathrm{n}=35 / 35\end{array}$ & $\begin{array}{l}\text { PGY1: } 11 \\
\text { PGY2: } 12 \\
\text { PGY3: } 12 \\
\end{array}$ & Medical students, PharmD students \\
\hline & & $\begin{array}{l}\text { Peds } \\
\mathrm{n}=24 / 24\end{array}$ & $\begin{array}{l}\text { PGY1: } 8 \\
\text { PGY2: } 8 \\
\text { PGY3: } 8 \\
\end{array}$ & $\begin{array}{l}\text { Medical students, nursing students, clinical psychology } \\
\text { students }\end{array}$ \\
\hline \multirow{3}{*}{9} & \multirow{3}{*}{ Midwest } & $\begin{array}{l}\mathrm{FM} \\
\mathrm{n}=28 / 28\end{array}$ & $\begin{array}{l}\text { PGY1: } 11 \\
\text { PGY2: } 8 \\
\text { PGY3: } 9\end{array}$ & $\begin{array}{l}\text { Medical students, physician assistant students, PharmD } \\
\text { students, clinical psychology students, MA students }\end{array}$ \\
\hline & & $\begin{array}{l}\mathrm{IM} \\
\mathrm{n}=43 / 81\end{array}$ & $\begin{array}{l}\text { PGY1: } 15 \\
\text { PGY2: } 13 \\
\text { PGY3: } 15\end{array}$ & $\begin{array}{l}\text { Medical students, nurse practitioner students, physician } \\
\text { assistant students, PharmD students }\end{array}$ \\
\hline & & $\begin{array}{l}\text { Peds } \\
\mathrm{n}=47 / 47\end{array}$ & $\begin{array}{l}\text { PGY1: } 16 \\
\text { PGY2: } 15 \\
\text { PGY3: } 16\end{array}$ & Medical students \\
\hline
\end{tabular}

*Pediatric residents do not conduct their continuity practice at this PACER clinic but spend time there during an ambulatory rotation. 
The total number of residents by discipline and career choices in terms of primary care, subspecialty care and hospitalist care among residents are outlined in Table 2, which shows that $89.2 \%$ of FM residents, $58.5 \%$ of IM residents and $67.1 \%$ of Peds residents were exposed to comprehensive colearning in their residency continuity clinics. In terms of career choice, among FM resident graduates an estimated $87.1 \%$ chose to go into primary care compared to $12.4 \%$ of IM resident graduates and $36.5 \%$ of Peds resident graduates. About $5 \%$ (4.9\%) of FM resident graduates were estimated to go into subspecialty care and $7.8 \%$ into hospitalist care. Over $50 \%$ (50.3\%) of IM resident graduates were estimated to go into subspecialty care and $37.2 \%$ into hospitalist care, while in pediatrics $44.2 \%$ chose subspecialty care, and $19.3 \%$ chose hospitalist care (Table 2).

Our analysis of conditions that influence collaboration among the primary care disciplines yielded several themes (Table 3), all but one involved both supportive and challenging conditions. For example, the supportive condition related to the relationship development theme is that establishing respectful relationships helps to develop a commitment for change among the three disciplines and across all health professions, while a challenging condition is that schools and departments have different leaders with different priorities, goals, and mechanisms of change, and the overall chains of command are ambiguous. Joint educational activities, such as shared orientation sessions and joint grand rounds helps build relationships among both faculty and learners for future collaboration.

Professional identity, defined as the qualities, beliefs or attitudes one has that makes them unique emerged as a theme. On the supportive side, it takes work to think more creatively about how the primary care disciplines fit into one another's worlds, where different cultures and language affect the ease by which they create a common understanding of their identities. Challenges include that similarities among the disciplines may not be readily evident, and by working together there is a concern that they will lose their identity and be indistinguishable from one another (Table 3).

Commonality of goals or shared mission, defined as the state of having and then sharing ideas about the future desired results, emerged as a theme. Supportive conditions include seeing value in meeting together and sharing ideas about how to address common problems like the impact of social determinants of health on patients. By joining together, the three disciplines have a bigger voice and avoid competing for resources. The challenging elements include variability in each disciplines' commitment to primary care and in their journey toward interprofessional collaborative practice, which makes it difficult for these disciplines to unite around a common goal.

Presence or absence of institutional support/alignment was also a theme with both supportive and challenging conditions. Strong alignment with institutional initiatives creates unifying bonds for the primary care disciplines. When the health system aligns their mission with care for the underserved, a cohesive, balanced, and specific focus on building the primary care workforce emerges. However, when the three primary care disciplines are aligned with different hospital or clinic systems, cohesion is challenging.

Another emergent theme involved aspects of residency training, defined as features of residency education that are influential across disciplines. Several sites identified that a desire or ability to get residents in clinic more often reflects a more intentional approach to training primary care physicians. Active resident involvement in the change process and in care teams was another supportive condition. Variability in schedules of multiple learners create inconsistencies in the educational environment, limited time in the clinic, and inherent tension between educational and clinical priorities create further challenges for residency programs.

Table 2: Resident Exposure to PACER Clinics and Resident Career Choice by Discipline

\begin{tabular}{|l|c|c|c|}
\hline \multicolumn{1}{|c|}{ Exposure to Practice-based Colearning } & $\begin{array}{c}\text { Family Medicine } \\
\mathbf{( n = 2 7 9 )} \\
\mathbf{n}(\mathbf{\%})\end{array}$ & $\begin{array}{c}\text { Internal Medicine } \\
\mathbf{( n = 7 3 1 )} \\
\mathbf{n}(\%)\end{array}$ & $\begin{array}{c}\text { Pediatrics } \\
\mathbf{( n = 4 7 7 )} \\
\mathbf{n}(\%)\end{array}$ \\
\hline $\begin{array}{l}\text { Residents exposed to ambulatory training in PACER clinics } \\
\text { with colearning model }\end{array}$ & $249(89.2 \%)$ & $428(58.5 \%)$ & $320(67.1 \%)$ \\
\hline $\begin{array}{l}\text { Residents exposed to ambulatory training in non-PACER } \\
\text { clinics }\end{array}$ & $30(10.8 \%)$ & $303(41.5 \%)$ & $157(32.9 \%)$ \\
\hline Career Choice_Percent and Number & $\begin{array}{c}(\mathbf{n = 2 4 3 )} \\
\mathbf{n}(\mathbf{\%})\end{array}$ & $\begin{array}{c}\mathbf{( n = 7 3 1 )} \\
\mathbf{n ~ ( \% )}\end{array}$ & $\begin{array}{c}\mathbf{( n = 4 7 7 )} \\
\mathbf{n}(\%)\end{array}$ \\
\hline Primary care & $212(87.2 \%)$ & $91(12.4 \%)$ & $174(36.5 \%)$ \\
\hline Subspecialty care & $12(4.9 \%)$ & $368(50.3 \%)$ & $211(44.2 \%)$ \\
\hline Hospitalist care & $19(7.8 \%)$ & $272(37.2 \%)$ & $92(19.3 \%)$ \\
\hline
\end{tabular}

*Number decreased due to missingness. 
The emergent theme of stressors only had challenging conditions. Competing demands that could unite the primary care disciplines cause fracturing, resulting in shifting priorities and threats to collaboration. Disruptive forces of frequent transitions, such as changes in electronic health records; shifting roles for faculty, and increases in the number of learners that sites are asked to take make it difficult for the three disciplines to come together. Lastly, lack of resources such as funding to hire a coordinator to help with interprofessional activities is a challenge leading to a level of chaos that becomes inherently acceptable but erodes or prevents collaboration and results in significant burnout.

\section{Discussion}

To our knowledge, this is the largest study conducted to date on conditions likely to influence collaboration among the primary care disciplines as they prepare the future primary care workforce. Nine teams of faculty from FM, IM, and Peds residencies and other health professions training programs across the country worked collaboratively to design interprofessional practice-based learning activities in transformed primary care clinics. The specific results of the interventions that were part of this study are described elsewhere, but these efforts innovatively transformed training, at least in part, for nearly $1,000(n=997)$ residents over the 3 -year period.

This study is especially important as new evidence indicates that interprofessional education and teambased care can improve both patient outcomes and population health, ${ }^{17}$ as well as other important elements of the triple aim. ${ }^{15}$ Even more crucial is the question about whether we are creating a primary care workforce that will meet the needs of the US population as growth among aging Americans will increase health care utilization. ${ }^{1-4}$ Our finding that

Table 3: Conditions That Support or Challenge Primary Care Disciplines Abilities to Unite to Transform Residency Training

\begin{tabular}{|c|c|c|}
\hline $\begin{array}{l}\text { Emergent } \\
\text { Themes }\end{array}$ & Supportive Conditions & Challenging Conditions \\
\hline $\begin{array}{l}\text { Relationship } \\
\text { development } \\
\text { (defined as the } \\
\text { evolutionary } \\
\text { process of being } \\
\text { connected } \\
\text { across the three } \\
\text { primary care } \\
\text { disciplines) }\end{array}$ & $\begin{array}{l}\text {-Establishing respectful relationships helps to develop a } \\
\text { commitment for change both among the three disciplines } \\
\text { and across health professions [Site \#3]. } \\
\text {-Many sites are still building trusting relationships } \\
\text { among the primary care team members. This cannot be } \\
\text { achieved without routine interactions-they need to find } \\
\text { the best way to work together on a specific project. As } \\
\text { they discuss things, they realize that they have more in } \\
\text { common than they thought. [Site \#9]. } \\
\text {-The process of developing interdisciplinary clinic } \\
\text { models (FM, IM, Peds, PA, psychiatry, dental hygiene, } \\
\text { and counseling), results in a level of comfort interacting } \\
\text { with each other that was a unifying force in their work } \\
\text { together [Sites \#2, 5]. } \\
\text {-Joint educational activities (e.g. orientation, grand } \\
\text { rounds, training modules) for faculty and learners } \\
\text { helps to build relationships across disciplines for future } \\
\text { collaboration [Sites \#2, } 4,6,7,9 \text { ]. }\end{array}$ & $\begin{array}{l}\text {-Every school/department, including } \\
\text { interdisciplinary schools, has a different } \\
\text { leader with different priorities and goals. } \\
\text { The mechanisms of change and the chain of } \\
\text { command are ambiguous [Sites \#1, 3], which } \\
\text { results in stalling of activities. } \\
\text {-The process of working on the } \\
\text { interdisciplinary clinic has not trickled } \\
\text { down to how they interact in their discipline } \\
\text { specific clinics [Site \#2]. } \\
\text {-When there is an imbalance in what each } \\
\text { discipline is doing to support the overall } \\
\text { PACER effort, a sense of unity across } \\
\text { disciplines does not progress [Sites \#3, 4]. }\end{array}$ \\
\hline $\begin{array}{l}\text { Professional } \\
\text { identity } \\
\text { (defined as the } \\
\text { qualities, beliefs } \\
\text { or attitudes one } \\
\text { has that makes } \\
\text { them unique) }\end{array}$ & $\begin{array}{l}\text {-It takes work to think more creatively about how to fit } \\
\text { in each other's world. Different disciplines need to learn } \\
\text { about the culture and language of the other disciplines } \\
\text { and how each of their different clinics function to create } \\
\text { a common understanding of their identities [Site \#3]. }\end{array}$ & $\begin{array}{l}\text {-Similarities among the three disciplines are } \\
\text { not readily evident by all members within } \\
\text { them - it takes time for this to develop } \\
\text { and there is concern that they will lose the } \\
\text { identity unique to their own disciplines } \\
\text { [Sites \#3, 7]. } \\
\text {-Concern that by working together and } \\
\text { having their residents work together, they } \\
\text { will be indistinguishable from each other } \\
\text { or that they will not be creating the right } \\
\text { resident for their discipline [Sites \#3, 4]. } \\
\text {-When there is a perception that the } \\
\text { cultures of the disciplines are very different, } \\
\text { there is skepticism that one can benefit } \\
\text { much from another. They appear to know } \\
\text { that they could learn something from the } \\
\text { other disciplines, but do not want to mimic } \\
\text { them [Site \#3, 7]. }\end{array}$ \\
\hline
\end{tabular}




\begin{tabular}{|c|c|c|}
\hline $\begin{array}{l}\text { Emergent } \\
\text { Themes }\end{array}$ & Supportive Conditions & Challenging Conditions \\
\hline $\begin{array}{l}\text { Commonality } \\
\text { of goals or } \\
\text { shared mission/ } \\
\text { communication } \\
\text { (defined as the } \\
\text { state of having } \\
\text { and then } \\
\text { sharing ideas } \\
\text { about the future } \\
\text { and desired } \\
\text { results) }\end{array}$ & $\begin{array}{l}\text {-Developing and communicating common goals among } \\
\text { the three disciplines and across health professions [Sites } \\
\text { \#3, 4, 7]. } \\
\text {-Seeing value in meeting together to discuss practice } \\
\text { transformation, eg, sharing ideas about how to best } \\
\text { address things like social determinants of health, } \\
\text { transitions in care planning, how they share practice } \\
\text { data in their clinics [Sites \#1, } 3,4,7 \text { ]. } \\
\text {-Meeting routinely can enhance cohesiveness of the } \\
\text { three disciplines in their work together [Sites \# } 2,3,4 \text {, } \\
5,7] \text {. } \\
\text {-By joining together (such as when creating a uniform } \\
\text { approach to specialty referrals), they have a bigger voice } \\
\text { and are at the table at higher level meetings to keep the } \\
\text { primary care perspective visible [Site \#5, } 6 \text { ]. } \\
\text {-Staying unified plays an important role in preventing } \\
\text { the leadership from doing separate deals with each } \\
\text { discipline, which could potentially create more division } \\
\text { [Site \#5]. } \\
\text {-When dialogue expands to discussions of institutional } \\
\text { policies toward primary care, it is easier to become } \\
\text { united [Site \#5]. } \\
\text {-A strong leader of their efforts makes a difference } \\
\text { for engagement, momentum and commitment to keep } \\
\text { collaborating [Sites \#3, } 7 \text { ]. } \\
\text {-When there is a strong commitment to primary care } \\
\text { from leadership among all } 3 \text { disciplines, it makes it } \\
\text { easier to coalesce around a common goal/mission (eg, } \\
\text { providing care to indigent populations) [Sites \#4, } 5,8,9 \text { ]. }\end{array}$ & $\begin{array}{l}\text {-Variability in each discipline's commitment } \\
\text { to primary care makes it difficult for the } \\
\text { team to come together around common goals } \\
\text { [Sites \#1, 3, 4] } \\
\text {-Inability to communicate effectively with } \\
\text { leadership in the institutional/health system } \\
\text { can significantly erode efforts to advance } \\
\text { around a united mission [Site \#4]. } \\
\text {-If one discipline is farther along the } \\
\text { interprofessional collaborative practice } \\
\text { journey, this presents an additional } \\
\text { challenge for the team to find a joint project } \\
\text { to coalesce around where balanced co- } \\
\text { learning can occur [Sites \#1, 4]. } \\
\text {-Identifying a unifying project or a } \\
\text { commonality of purpose and communicating } \\
\text { this across all three disciplines to work on } \\
\text { can be challenging [Sites \#1, 4] } \\
\text {-Pulling the trigger in terms of } \\
\text { implementing actual change, even with } \\
\text { common goals is hard [Site \#1] }\end{array}$ \\
\hline $\begin{array}{l}\text { Presence or } \\
\text { absence of } \\
\text { institutional } \\
\text { support/ } \\
\text { alignment } \\
\text { (defined as } \\
\text { a position of } \\
\text { agreement/ } \\
\text { alliance or lack } \\
\text { thereof with the } \\
\text { institution that } \\
\text { may or may not } \\
\text { be associated } \\
\text { with financial } \\
\text { resources) }\end{array}$ & $\begin{array}{l}\text {-Gaining institutional support for change is easier when } \\
\text { primary care disciplines unite [Sites \# } 2,3,6,7,8] \text {. } \\
\text {-Strong alignments with other institutional initiatives } \\
\text { create unifying bonds [Sitse \#2, } 3,6,7 \text { ]. } \\
\text {-Access to stable institutional resources, such as funding } \\
\text { to hire a coordinator to help with planning is important } \\
\text { for change [Sites \#2, } 3,8] \text {. } \\
\text {-When health systems align in their mission, especially } \\
\text { around care for the underserved, cohesion, balance, and } \\
\text { a specific focus on building the primary care workforce } \\
\text { across FM, IM and Peds emerges [Sites \#4, } 5,6,7,8 \text { ]. } \\
\text {-When leaders of primary care departments understand } \\
\text { institutional politics and dynamics together, they are } \\
\text { able to strategize together for the sake of primary care } \\
\text { in the institution [Sites \#5, 8]. } \\
\text {-When primary care physicians have leadership roles } \\
\text { in the medical school, they can leverage their work } \\
\text { with other institutional efforts and gain support for } \\
\text { sustainability [Site \#8]. }\end{array}$ & $\begin{array}{l}\text {-If the organizational structure of the } \\
\text { overarching institution is very rigid or } \\
\text { standardized, then working together } \\
\text { within and across disciplines can be very } \\
\text { challenging [Site \#3]. } \\
\text {-When the three primary care disciplines } \\
\text { are aligned with different health systems, } \\
\text { further challenges exist that prevent them } \\
\text { from uniting - This is especially true for any } \\
\text { institution whose leadership does not view } \\
\text { the primary care disciplines as united [Sites } \\
\text { \#1, 8]. } \\
\text {-When potential available resources are } \\
\text { unknown or consistently refused, even after } \\
\text { promises made about support [Site \#1], } \\
\text { there is a lack of trust in the institution's } \\
\text { leadership that erodes relationships. }\end{array}$ \\
\hline
\end{tabular}


Table 3: Continued

\begin{tabular}{|c|c|c|}
\hline $\begin{array}{l}\text { Emergent } \\
\text { Themes }\end{array}$ & Supportive Conditions & Challenging Conditions \\
\hline $\begin{array}{l}\text { Aspects of } \\
\text { residency } \\
\text { training } \\
\text { (defined as } \\
\text { features of } \\
\text { residency } \\
\text { education that } \\
\text { are influential } \\
\text { across } \\
\text { disciplines) }\end{array}$ & $\begin{array}{l}\text {-Desire or ability to have residents spend more time in } \\
\text { clinic reflects a more intentional approach to training } \\
\text { primary care physicians [Sites \# } 1,2,3,7,9] \text { ]. } \\
\text {-IM, Peds and FM residents interact often on inpatient } \\
\text { rotations [Sites \#1, } 2,6,7] \text {. } \\
\text {-Active resident involvement in change processes makes } \\
\text { a huge difference [Sites \#3, } 8 \text { ]. } \\
\text {-Attempting some change, such as: } 1 \text { ) including learners } \\
\text { more often in their Care Team; and } 2 \text { ) doing more case- } \\
\text { based learning together helps to create momentum that } \\
\text { can provide a stronger foundation upon which to build } \\
\text { [Sites \#1, 2]. } \\
\text {-Program directors at the GME level from the different } \\
\text { disciplines have collaborated in preparation for things } \\
\text { like CLER visit/NCQA, which were unifying aspects of } \\
\text { their work together [Sites \#2, } 5,9] \text { ]. } \\
\text {-When the culture of community-oriented primary care } \\
\text { is strong, the set of training programs appears to be very } \\
\text { learner- and patient-centric [Sites \#2,9]. }\end{array}$ & $\begin{array}{l}\text {-Variability in schedules of multiple } \\
\text { learners creates regular inconsistencies in } \\
\text { the educational environment [Site \#3]. } \\
\text {-Figuring out how to optimize care } \\
\text { coordination among multiple learners is } \\
\text { challenging [Site \#3]. } \\
\text {-Limited clinic time results in training that } \\
\text { is more focused on hospitalist or specialty } \\
\text { career development. This is especially } \\
\text { evident in IM and Peds [Sites \#1, 3, } 7 \text { ]. } \\
\text {-The inherent tension between educational } \\
\text { priorities and clinical priorities is erosive } \\
\text { - there is a perception that these cannot } \\
\text { coexist in a meaningful way [Sites \#1, } 4,5 \text {, } \\
\text { 9]. } \\
\text {-When the residents in the } 3 \text { disciplines } \\
\text { don't interact often [Site \# } 4,9 \text { ] there is no } \\
\text { reason for the faculty to interact. }\end{array}$ \\
\hline $\begin{array}{l}\text { Impact of } \\
\text { external } \\
\text { support (defined } \\
\text { as assistance } \\
\text { derived from } \\
\text { outside the } \\
\text { institution) }\end{array}$ & $\begin{array}{l}\text {-When the three primary care disciplines have a } \\
\text { track record of collaborating on prior funded projects } \\
\text { (HRSA, SBIRT), collaborative activities can be unifying; } \\
\text { however, parallel play, where colocation often exists but } \\
\text { interactions are minimal, still does occur [Sites } \# 2,4,5 \text {, } \\
6,7,9 \text { ]. } \\
\text {-Programs gain momentum when they participate in } \\
\text { regional primary care residency training efforts [Sites } \\
\# 1,2,4,7 \text { ] }\end{array}$ & $\begin{array}{l}\text {-Easier to work on funded grant than try to } \\
\text { move an unfunded effort [Site \#1] }\end{array}$ \\
\hline $\begin{array}{l}\text { Location } \\
\text { (defined as } \\
\text { physical locale) }\end{array}$ & $\begin{array}{l}\text {-Colocation among the primary care disciplines makes } \\
\text { a difference in terms of the ease and frequency of } \\
\text { interactions [Sites \#2, 3,6, 8], though this did not occur } \\
\text { to the level expected at one site [Site \#8]. } \\
\text {-Having two or three of the primary care disciplines } \\
\text { integrated in the same clinic facilitates interdisciplinary } \\
\text { teamwork and relationship building [Sites \#2, 5]. }\end{array}$ & $\begin{array}{l}\text {-Physically distant locations make meeting } \\
\text { together hard and when IT solutions don't } \\
\text { work well, momentum is lost [Site \#1, } 4,8 \text {, } \\
\text { 9]. }\end{array}$ \\
\hline $\begin{array}{l}\text { Stressors } \\
\text { (defined as } \\
\text { an activity } \\
\text { or event that } \\
\text { interferes with } \\
\text { a steady state } \\
\text { of equilibrium) }\end{array}$ & & $\begin{array}{l}\text { - Competing demands that could unite them } \\
\text { can cause fracturing (e.g., switching to a new } \\
\text { electronic medical record [Site \#3] resulting } \\
\text { in delays and loss of momentum. } \\
\text {-Primary care leaders struggle with } \\
\text { competing demands, which results in change } \\
\text { priorities and collaboration dropping off } \\
\text { their radar resulting in delays and loss of } \\
\text { momentum [Site \#1]. } \\
\text {-Disruptive forces of transitions, shifting } \\
\text { roles for faculty, and increases in learner } \\
\text { burden make it difficult to come together } \\
\text { [Sites \#6, 8]. } \\
\text {-Lack of resources for primary care is a } \\
\text { significant challenge that leads to a level of } \\
\text { chaos that somehow becomes acceptable but } \\
\text { this erodes or prevents any chance of uniting } \\
\text { [Site \#6] and results in significant burnout. }\end{array}$ \\
\hline
\end{tabular}


only $12.4 \%$ of internists and $36.5 \%$ of pediatricians are choosing primary care careers is consistent with other literature about trends in selecting general internal medicine versus subspecialty or hospitalist care among third-year residents. ${ }^{7}$ Though the numbers are small, we found that some family physicians are also choosing these career paths, which is likely a change from a decade ago. One study from 2005 found that about $3 \%$ of hospitalists were family physicians, ${ }^{21}$ and our study shows that this has more than doubled. This is discouraging, as fewer primary care physicians appear to be entering the workforce, a finding our study also revealed.

The emerging qualitative themes make an important contribution to existing literature by identifying serious impediments to working together to produce an effective primary care physician workforce. Physician participants varied widely in their prior interdisciplinary relationships, some of which were paper-thin. They don't have an agreed-upon identity as primary care physicians. They often don't share the same goals and vary substantially in their commitment to deliver primary care. Their lack of alignment with one another appears to fracture their ability to garner institutional support. Scheduling shared education, clinic-based learning, and quality improvement activities are all considerable challenges. They are often not colocated geographically, are overextended, overworked, underpaid relative to their physician peers in other specialties, and perceive themselves to be underappreciated. Despite these overwhelming challenges, they are well positioned to collaborate and often welcomed other professions willing to work with them to create and execute outstanding primary care. Primary care residencies did agree to work together, but they underestimated challenges involved in making this happen and often did not have existing infrastructures, processes, and collaborative activities in place to facilitate implementation of their PACER plans.

The three primary care disciplines will need to collaborate with one another and with other disciplines if the triple aim is to be achieved. This represents a policy emergency that needs immediate attention, before the country settles back into the 1950s and rediscovers the limits of fragmented subspecialization and unbalanced tertiary care. It will be disheartening if we don't figure out how to utilize the assets of the largest primary care workforce ever to exist in the United States, which has taken 50 years to establish. Leaders of the three boards must guide these actions and communicate this need effectively among their diplomates.

We did find features that enabled collaboration and these should be developed. They include relationship development, communication of shared goals, alignment with health system, and other institutional initiatives. Many primary care teams had not interacted before PACER, so the development of valued relationships was important for supporting joint activities. Identifying common goals for the disciplines to work on together was often challenging, as there were differences in the extent to which primary care was perceived as a priority, and a shared mental model about what primary care delivery looks like at the institution or within the residencies was often lacking.

Professional identity was an emergent theme that can create challenges for joint work. Identity formation occurs dynamically through socialization among individuals joining a medical community of practice. ${ }^{22}$ Some sites raised concerns that an interdisciplinary socialization process between faculty and/or residents, may cause them to lose their disciplinary uniqueness. This could result in them becoming indistinguishable or that they will not be creating the "right" resident for their discipline. In addition, when a perception exists that the cultures of the disciplines are different, there is skepticism that one can benefit from another or if they could learn something from the other disciplines, they do not want to mimic them. Understanding and respecting the uniqueness of each discipline's culture, while finding strength and value in the professional identity of a primary care physician is needed if collaboration is to be enhanced.

Another emergent theme was the significant stress that primary care training sites are under in today's health care environment. Competing demands, lack of resources, and other stressors contribute to burnout, the extent to which may further affect medical students' decisions to enter primary care as a career choice. ${ }^{23}$ It does seem that fostering alignment of the primary care disciplines toward transforming the clinics where learners of many disciplines are trained has great potential in strengthening their abilities to practice efficiently and effectively in teams.

The strengths of this study include the geographic representation of primary care residency programs and that participating residencies varied in size and contextual features that generated rich qualitative data. Another strength is the very high survey response rates we obtained. Weaknesses include our inability to assess trainees present in the nonPACER clinics, though we expect it is likely that medical students and other learners were present there. Another weakness is that not all residents were trained in PACER clinics, and we did not characterize their career choices according to whether their training occurred in the PACER clinics. However, we could look into this in a future study. We also used field notes, rather than transcripts, for qualitative data collection because of costs. This resulted in an inability for us to use actual quotes when presenting exemplars. However, the use of independent coders and consensus meetings represent robust analyses. Lastly, the design of this study did not include 
a comparison group, making it impossible for us to determine causal relationships. It is very difficult to implement randomized designs into educational settings, which is why we chose a mixed-methods approach to collect rich data.

In conclusion, it is clear that primary care plays a vital role in the health of the US population, that innovations in training, especially toward preparing health professionals to be team-based care ready, not just in hospital settings but also in ambulatory settings, are also needed. We learned that uniting primary care disciplines in this work is not easy to accomplish and that several supporting and challenging conditions exist that may foster or impede success.

FUNDING STATEMENT: This work was supported by the American Board of Family Medicine Foundation, the American Board of Internal Medicine, the American Board of Pediatrics Foundation, the Josiah Macy Jr Foundation, and the Accreditation Council for Graduate Medical Education.

CONFLICT OF INTEREST: None of the authors have conflicts of interest to declare.

CORRESPONDING AUTHOR: Address correspondence to Dr Patricia A. Carney, Professor of Family Medicine, Oregon Health and Science University, 3181 SW Sam Jackson Park Rd. MC: FM, Portland, OR 97239. 503-4949049. Fax: 503-494-2746. carneyp@ohsu.edu.

\section{References}

1. Petterson SM, Liaw WR, Phillips RL Jr, Rabin DL, Meyers DS, Bazemore AW. Projecting US primary care physician workforce needs: 20102025. Ann Fam Med. 2012;10(6):503-509.

2. Foster RS. Estimated financial effects of the "Patient Protection and Affordable Care Act," as amended. Baltimore, MD: Centers for Medicare and Medicaid Services; 2010.https:// www.cms.gov/ActuarialStudies/Downloads/ PPACA_2010-04-22.pdf. Accessed December 11, 2017.
3. Dill MJ, Salsberg ES. The Complexities of Physician Supply and Demand: Projections Through 2025. Washington, DC: Association of American Medical Colleges; 2008: http:// www.innovationlabs.com/pa_future/1/background_docs/AAMC\%20Complexities $\% 20$ of $\% 20$ physician $\% 20$ demand,\%202008.pdf. Accessed December 11, 2017.

4. Colwill JM, Cultice JM, Kruse RL. Will generalist physician supply meet demands of an increasing and aging population? Health Aff (Millwood). 2008;27(3)(suppl 1):w232-w241.

5. Council on Graduate Medical Education. 10th Report. Physician Distribution and Health Care Challenges in Rural and Inner-city Areas. Washington, DC: US Department of Health and Human Services, Health Resources and Services Administration; 1998.

6. Green LA, Dodoo MS, Ruddy G, Fryer GE, Phillips RL, McCann JL, O’Neil EH, Klein LS. The Physician Workforce of the United States: A Family Medicine Perspective. Washington, DC: The Robert Graham Center; 2004. http:// www.graham-center.org/PreBuilt/physician workforce.pdf. Accessed December 11, 2017.

7. Kozakowski SM, Travis A, Marcinek JP, Bentley A, Fetter GT Jr. Results of the 2017 National Resident Matching Program and the American Osteopathic Association Intern/ Resident Registration Program. Fam Med. 2017;49(9):679-685.

8. Rich EC. The physician workforce and counting what counts in primary care. Fam Med. 2018;50(8):579-582.

9. Green LA, Jones SM, Fetter G Jr, Pugno PA Preparing the personal physician for practice: changing family medicine residency training to enable new model practice. Acad Med. 2007;82(12):1220-1227.

10. Jones MD, Leslie MK, McGuinness GA. Residency review and redesign in pediatrics: new (and old) questions. Pediatrics. 2009;123(suppl 1):S1-S60.

11. Mladenovic J, Bush R, Frohna J. Internal medicine's Educational Innovations Project: improving health care and learning. Am J Med. 2009;122(4):398-404.

12. Carney PA, Eiff MP, Green LA, et al. Transforming primary care residency training: a collaborative faculty development initiative among family medicine, internal medicine, and pediatric residencies. Acad Med. 2015;90(8):1054-1060.
13. Eiff MP, Green LA, Holmboe E, et al. A model for catalyzing clinical and educational transformation in primary care: outcomes from a partnership among family medicine, internal medicine, and pediatrics. Acad Med. 2016;91(9):1293-1304.

14. PACER. Professionals accelerating clinical and educational redesign. www.pcpacer.org Accessed Sepetember 11, 2018.

15. Berwick DM, Nolan TW, Whittington J. The triple aim: care, health, and cost. Health Aff (Millwood). 2008;27(3):759-769. lenzuela S, et al. A Model for accelerating educational and clinical transformation in primary care by building interprofessional faculty teams. Findings from PACER [In Review].

17. Reeves S, Fletcher S, Barr H, et al. A BEME systematic review of the effects of interprofessional education: BEME Guide No. 39. Med Teach. 2016;38(7):656-668.

18. Barr H, Koppel I, Reeves S, Hammick M, Freeth D. (2005). Effective interprofessional education: Assumption, argument and evidence. Oxford, UK: Wiley Blackwell; 2005.

19. Johnson B, Christensen LB. Educational research: quantitative, qualitative, and mixed approaches. 4th ed. Thousand Oaks, CA: SAGE Publications; 2012.

20. Creswell JW. Qualitative inquiry and research design: choosing among five approaches. 2nd ed. Thousand Oaks, CA: Sage Publications Ltd; 2007.

21. Iqbal Y. Family medicine hospitalists: separate and unequal? Today's Hospitalist, May, 2017. https://www.todayshospitalist.com/Familymedicine-hospitalists-separate-and-unequal/ Accessed Septeber 21, 2018.

22. Cruess RL, Cruess SR, Boudreau JD, Snell L, Steinert Y. A schematic representation of the professional identity formation and socialization of medical students and residents: a guide for medical educators. Acad Med. 2015;90(6):718-725.

23. West CP. Turned off and burned out: what will it take for "front-line" medicine to tune back in? J Grad Med Educ. 2013;5(2):184-186. 